\title{
Revisitando las fuentes ideológicas del desarrollismo: Rogelio Frigerio y el marxismo argentino
}

\author{
Revisiting the ideological sources of the Developmentalism: \\ Rogelio Frigerio and the Argentine Marxism
}

\author{
Angel Cerra \\ Universidad de Buenos Aires, (Argentina) \\ mensajeroengriego@yahoo.com.ar
}

\begin{abstract}
Resumen
El artículo se propone investigar los elementos constitutivos del desarrollismo argentino utilizando la metodología de la Historia de las Ideas. Se discutirán, en primer lugar, distintas explicaciones alternativas sobre su gestación y el papel que en ella juegan las ideas previas del presidente Arturo Frondizi, la teoría del sistema de centro-periferia cepalino y el aparato conceptual de los denominados "teóricos del desarrollo". La crítica de estas definiciones nos permitirá explorar dos vías hermenéuticas distintas que sientan sus raíces en el espacio intelectual local: el industrialismo de Alejandro Bunge y la producción de escritores ligados al comunismo argentino, como Ernesto Giudici y dirigentes de escaso brillo, como Vittorio Codovilla. La combinación de estas dos tradiciones es la que explicaría la emergencia del desarrollismo bajo el liderazgo de Rogelio Frigerio. Se postula que las coincidencias entre las distintas corrientes modernizadoras o desarrollistas de las décadas de 1950/1960 se deben a la presencia de un tronco ideológico común, donde tendrían un papel principal, pero no exclusivo, el leninismo y la experiencia soviética.
\end{abstract}

\section{Palabras Clave}

Ideas; Desarrollismo; Argentina; Frigerio; Marxismo

\begin{abstract}
The article aims at exploring the constitutive elements of the Argentine developmentalism, by using the methodology of the history of ideas. To begin with, a large number of topics will be discussed: different alternative explanations about its gestation and the role president Arturo Frondizi's ideas play in it, the theory of the system of Centre-periphery (CEPAL), and the conceptual device introduced by the "development theorists." The critique of these definitions will contribute to examine two distinct hermeneutic ways which stem from the local intellectual space: Alejandro Bunge's industrialism and the production of writers linked to the Argentine communism, such as Ernesto Giudici, and opaque leaders, such as Vittorio Codovilla. It is the combination of both traditions that would explain the emergence of the developmentalism under the leadership of Rogelio Frigerio. It is postulated that the coincidences among the different modernizing or developmental trends from the 1950s/1960s grow out of the presence of an ideological common core, in which

Esta obra está sujeta a la Licencia Reconocimiento-NoComercial-CompartirIgual 4.0 Internacional de Creative Commons. http://creativecommons.org/licenses/by-nc-sa/4.0/




\section{Angel Cerra}

they would play a key role, though not an exclusive one, the Leninism and the soviet experience.

\section{Keywords}

Ideas; Developmentalism; Argentina; Frigerio; Marxism.

\section{Introducción}

El propósito del artículo es investigar los elementos formativos del desarrollismo argentino desde la perspectiva de la Historia de las Ideas. La discusión sobre esta corriente ideológica, sus características distintivas y fuentes de inspiración, se renueva cíclicamente al calor de distintos contextos políticos y académicos. En los últimos tiempos el interés sobre el desarrollismo se ha reavivado a la luz de las dificultades que atravesaron y atraviesan las dos vertientes dominantes de la política económica argentina reciente: el keynesianismo, proclive a un ensanchamiento de las funciones estatales, y el neoliberalismo, impulsor de la desregulación y del rol del mercado. A la luz del fracaso de ambas estrategias en la Argentina, la experiencia del gobierno encabezado por Arturo Frondizi y las ideas que lo inspiraron, aparecen como una alternativa que permitiría superar esas insuficiencias. Dejamos sentado que estas preocupaciones inmediatas no son las que motivan el artículo.

La cuestión desarrollista reconoce un derrotero anterior envuelto en polémicas y numerosas intervenciones desde el campo intelectual y la política. Preguntas tales como ¿la versión local del desarrollismo es elaborada o reelaborada por la dupla integrada por Arturo Frondizi y Rogelio Frigerio o es patrimonio del último y de los sucesivos think tanks por el coordinados? ¿el desarrollismo argentino forma parte de -o es simplemente un reflejo- de corrientes coetáneas que enfatizando las limitaciones del modelo primario exportador proponen la industrialización como salida exitosa? ¿es el resultado del contexto internacional de despliegue de las compañías transnacionales europeas y estadounidenses en los países periféricos? se han sucedido a lo largo de las últimas décadas.

De manera preliminar, expondremos nuestra posición, que será explicitada en las páginas siguientes: el desarrollismo argentino es una creación de Rogelio Frigerio imaginada con anterioridad a la experiencia de gobierno. Reconoce como fuentes principales de inspiración la obra de Alejandro Bunge y el grupo que lo acompañaba en la Revista de Economía Argentina y las ideas que circulaban en ámbitos vinculados al comunismo argentino en las décadas de 1930 y 1940 . Las semejanzas entre el desarrollismo argentino y las corrientes contemporáneas de la época a las que se intenta subsumirlo, no indicarían una transferencia o copia de esos estímulos externos, sino la pertenencia de todas esas ideologías a un tronco común.

A los efectos de la exposición, en primer lugar, presentaremos someramente algunos aspectos metodológicos vinculados con la Historia de las ideas; en segundo lugar, discutiremos los tópicos señalados como polémicos. Finalmente, describiremos las influencias que han impactado en la gestación del ideario desarrollista. 


\section{Revisitando las fuentes ideológicas del desarrollismo: Rogelio Frigerio y el marxismo argentino}

\section{La Historia de las Ideas}

La Historia de las ideas ha transitado el siglo XX y los inicios del siglo XXI de manera zigzagueante, observándose altas y bajas en su reconocimiento por parte de la comunidad científica (Dosse, 2006). Sus principales contendientes son aquellas corrientes que exaltan los condicionamientos materiales o sociopolíticos de la producción intelectual. Herederos del peor Marx o simplemente del evolucionismo decimonónico, se han preocupado por destacar que las ideas son el correlato mecánico de una determinada realidad económica o el resultado de la articulación de intereses que responden a la estructura de esa sociedad. También encontramos a los epígonos del namierismo, quienes sostienen que las decisiones de los hombres de estado dependen de intereses económicos básicos y directos. En todos los casos citados, las ideas se transformarían en instrumentos serviles de una supuesta realidad concreta y tangible. Por oposición, se encontrarían fuera del mundo sensible y, por lo tanto, no existirían o resultarían incomprobables

Así, muchos historiadores no solo han zanjado la compleja polémica entre Aristóteles y Platón sobre los modos del conocimiento y el carácter de la realidad: desconocen la importancia de las ideas en la vida social y política. Es particularmente acertada la crítica realizada por John Maynard Keynes a aquellos que subestiman el grado de autonomía de los intelectuales y de las ideas: todo estadista es esclavo, sin saberlo, de las concepciones de algún economista o filósofo político ya fallecido ${ }^{1}$.

El devenir de la Historia de las Ideas en el siglo XX presenta la tensión entre dos polos para su estudio. Por un lado, hallamos a aquéllos que sostienen la autonomía completa de las ideas, tal como ha sido postulada por Arthur Lovejoy. En este caso, la historia de Occidente estaría cruzada por una serie de ideas-fuerza que traspasan los siglos. Las ideas no solo resultan autónomas de su contexto socio-económico, sino también de los propios intelectuales que las generan. Por otro lado, encontramos a aquellos estudiosos que enfatizan la importancia del contexto de gestación de las ideas. No lo relacionan mecánicamente al modo del marxismo vulgar, sino exaltando las distintas interacciones que llevarían a la conformación de un cierto ideario. En este punto resulta especialmente relevante la noción de sociabilidad de Georg Simmel, quién enfatiza la posibilidad de autonomía por parte del intelectual de su posición social mediante un espacio público en el que comparte - y debate - con sus pares. La posición de Simmel, siempre que no se la lleve al

\footnotetext{
${ }^{1}$ La cita completa es: "Las ideas de los economistas y de los filósofos políticos, tanto si tienen razón como si no la tienen, son más poderosas de lo que se cree comúnmente. Sin duda el mundo está gobernado por poco más que esto. Los hombres prácticos, que se creen estar completamente al margen de influencias intelectuales, suelen ser esclavos de algún economista difunto. La locura que destilan los maniáticos de la autoridad que creen oír voces en el aire proceden de algún mal escritor académico de años atrás. Estoy seguro de que el poder de los intereses creados se suele exagerar mucho, comparado con la fuerza que tiene la introducción gradual de las ideas" (Keynes, 1998 Primera Edición en inglés 1936-, pág. 440) Anotamos que su archirrival intelectual, Friedrich August Von Hayek, compartía plenamente esa certeza.
} 


\section{Angel Cerra}

extremo de negar los condicionamientos que sufre toda producción intelectual, resulta útil para remarcar el carácter no determinado de la historia en general y de las ideas en particular (Dosse, 2006, págs. 56-57).

Desde mi perspectiva, la metodología de la Historia de las Ideas:

1. Plantea dos niveles de análisis. Uno, relacionado con el registro de los pensadores precedentes y a su influencia. Otro, que se vincula con el medio socio-cultural contemporáneo y a su interacción.

2. Distingue dos etapas en la construcción del conocimiento histórico, que a la vez se corresponde con distintos espacios disciplinarios. Éstas no son fácilmente separables y tampoco tenemos la certeza de que sea conveniente hacerlo. La primera etapa, es la que se relaciona con la filosofía o sociología de las ideas o con la historia de las doctrinas económicas. En ella se enfoca especialmente la génesis de las ideas, su contexto de aparición y la indagación alrededor de sus componentes de verdad, sobre el valor cognoscitivo. La discusión se ubica en términos lógicos. En una segunda etapa, las ideas son examinadas por su influencia sobre la sociedad en que son generadas, rescatadas o resignificadas. Es decir, alude al proceso por el cual se transforman en sistemas de creencias o ideologías. Como afirma Sartori, "las ideologías ya no son ideas -ideas sometidas a la jurisdicción de la lógica y al tamiz de la verificación-, sino más bien "ideas convertidas en palancas sociales", ideas convertidas en ideales dirigidos a la acción". Podríamos incluso afirmar: en el plano ideológico las ideas no son tratadas lógicamente -con fines cognoscitivos-, sino que, por el contrario, se tratan persuasivamente con fines de praxis-lógica. Pero si las ideologías son ex ideas, ideas-ya-no-ideas, y, por lo tanto, "ideas que ya no son pensadas" entonces se pone en evidencia la vinculación entre ideología y creencia" (Sartori, 1999 -Primera Edición en español 1992-, pág. 122)

Insistimos en la necesidad de no separar las dos etapas del análisis de las ideas, pero postulo que el enfoque histórico debe centrarse en: a) la búsqueda de los elementos formativos de las mismas, tanto desde el plano de los antecedentes intelectuales como al contexto socio-cultural de gestación b) el examen de sus mecanismos de transmisión, su conversión total o parcial en sistemas de creencias y su influencia como ideologías sobre las sociedades del presente y del futuro.

En cuanto a la metodología a emplear para el abordaje del objeto de investigación delimitado en el párrafo precedente, la propuesta involucra dos tareas que se corresponden con los apartados a) y b). Para la búsqueda de los elementos formativos, consideramos que el camino elegido por Nisbet es el más adecuado, si bien introduciría algunas modificaciones en su propuesta metodológica. El eminente sociólogo estadounidense postula tres perspectivas para encarar la Historia de las Ideas. La primera de ellas involucra los elementos biográficos de los autores estudiados, "lo que permite comprender las fuerzas motivadoras de la evolución 


\section{Revisitando las fuentes ideológicas del desarrollismo: Rogelio Frigerio y el marxismo argentino}

intelectual, esas percepciones, intuiciones profundas y descubrimientos que proceden únicamente de seres individuales" (Nisbet, 1977 -Primera Edición en Inglés 1966-, pág. 15) Este procedimiento contiene el riesgo -para Nisbet- de hacer una biografía del pensamiento y pierde de vista las relaciones, estructuras e influencias de las ideas entre sí, que superan ciertamente a las circunstancias de su gestación.

La segunda perspectiva estudia las escuelas, los sistemas, los ismos. La riqueza de este enfoque es que permite captar la globalidad y coherencia de los conjuntos de ideas, pero también contabiliza en el Debe un cierto reduccionismo y mutilación tanto de sus elementos básicos -las ideas- como de las contradicciones existentes entre los distintos autores que integran la corriente de pensamiento.

Finalmente, existe una tercera vía de análisis, que se sustenta en las ideas, elementos constitutivos de los sistemas. Permite realizar una búsqueda más ambiciosa a través de la historia, estableciendo regularidades y modificaciones de un concepto. Si bien es la preferida por Nisbet, podríamos que su excesiva amplitud temporal atenta contra el examen del contexto de génesis del concepto y su articulación con otras ideas. Para expresarlo de otra manera: si la pretensión del estudioso es examinar los elementos de verdad de un término, seguramente la última vía debe ser la escogida. Pero, como historiadores que consideramos que la distinción entre hechos y mentalidades es por lo menos discutible, resulta necesario rescatar el marco social en que las ideas germinaron para poder seguir la línea que nos conduce a su reelaboración, síntesis y difusión como sistemas de creencias.

Además, la práctica de la labor historiográfica demuestra que finalmente, la biografía, el contexto de generación, las vinculaciones con otras ideas y con otros autores, son factores explicativos esenciales y que ninguna perspectiva -ni aún aquella que postula el estudio independiente de las ideas-elemento- puede soslayarlos.

Procuraremos entonces combinar las dos primeras propuestas metodológicas: por un lado, bucear en la biografía intelectual de Rogelio Frigerio; por el otro, relacionar sus ideas con las corrientes contemporáneas denominadas laxamente como industrialistas, desarrollistas o modernizadoras.

En los apartados siguientes discutiremos -nuevamente- la cuestión de la primacía intelectual de Rogelio Frigerio y sus grupos en la creación del desarrollismo argentino.

\section{La -no- participación de Arturo Frondizi en la elaboración de las ideas desarrollistas}

Arturo Frondizi y Rogelio Frigerio conformaron un binomio político inseparable durante varias décadas, con mayor o menor peso en la realidad argentina. Sólo tuvieron acceso al poder en el período 1958-1962, cuando llevaron a la práctica las ideas conocidas en nuestro medio como desarrollismo. Su simbiosis era notable, planteándose una división de tareas: en la faz pública, la figura visible era Frondizi, 
mientras las sombras - incluyendo en estas no solo las negociaciones políticas non sanctas, sino también el armado ideológico - le pertenecían a Frigerio.

A pesar de no encontrarse evidencia acerca de la participación de Arturo Frondizi en la construcción de la ideología desarrollista, se la ha reiterado de manera inconmovible. Como detallaremos, las inconsistencias de esta posición son notorias. Ello no ha sido obstáculo para continuar enunciándola de manera insistente. Sin ningún argumento, se ha sostenido la formación de una sociedad ideológica entre el presidente y su compañero de ruta en la política.

Quizás la popularidad de la versión que adjudica a Frondizi un rol significativo en la construcción de la ideología desarrollista se vincule con el prestigio de alguno de sus sostenedores. En un trabajo clásico sobre el rol de las fuerzas armadas en la política argentina Alain Rouquié parece atribuir al grupo frigerista la primacía ideológica: "El frondizismo, término que aparece entonces, se forja en realidad fuera del partido y sus comités: el programa desarrollista fue elaborado por el brain trust de Frigerio, integrado por hombres de negocios, jóvenes empresarios y técnicos modernistas". Pero luego se desdice parcialmente: "Porque Frondizi y Frigerio habían descubierto la poción mágica que curaría todos los males del país: la industrialización a marcha forzada, por cualquier medio y a cualquier costo" (Rouquié, 1986, pág. 153)

En un trabajo reciente sobre Juan José Real, integrante de los think tanks de Frigerio, Aníbal Jáuregui afirma que el corpus de ideas desarrollistas:

\section{“... fue cimentándose a partir de la Intransigencia Radical a mediados de la década de 1950 pero se construyó con los materiales que le fue proporcionando el transcurso de la historia y que definió un lugar para el grupo desarrollista en el contexto político argentino. Si bien sus ideas podrían inscribirse en la economía del desarrollo y, por ende, en el keynesianismo, incorporó algunas singularidades de interés por su ligazón al pensamiento socialista" (Jáuregui, 2016, págs. 127-128)}

Obsérvese que la filiación se establece a través de la Intransigencia Radical - es decir, por la corriente política liderada por Frondizi- y que se considera el resultado de la mezcla de keynesianismo - en su derivación por la "economía del desarrollo"con el socialismo, quizás por resultar un tanto fuerte la utilización de la palabra comunismo en la propuesta. Figuras como Juan José Real serían las que aportarían el "socialismo" al desarrollismo.

Por el otro lado, intelectuales de peso como Carlos Altamirano resaltan el predominio de Frigerio y su grupo en la formulación del desarrollismo argentino. ${ }^{2}$

\footnotetext{
${ }^{2}$ Sin ser taxativa, la opinión de Altamirano privilegia la figura de Frigerio "Es difícil determinar el papel respectivo de Frondizi y Frigerio en la elaboración de la amalgama ideológica que con el tiempo se identificaría con sus nombres y con el término de desarrollismo, aunque todos los indicios hacen pensar que el primero fue quien acogió las ideas del segundo. Hasta 1956...Frondizi era, ideológicamente hablando, el representante político más conspicuo de la conjunción de laborismo de izquierda -este filón se resumía en la idea de "democracia económica"- antiimperialismo latinoamericanista y democratismo político que el mismo había contribuido a definir como bagaje de la llamada Intransigencia Radical" (Altamirano, 1998)
} 


\section{Revisitando las fuentes ideológicas del desarrollismo: Rogelio Frigerio y el marxismo argentino}

¿Por qué decimos que Rogelio Frigerio y no Arturo Frondizi es el autor del credo desarrollista? Enunciaremos una serie de ideas-fuerza que caracterizan a esta ideología, tal como fueron formuladas por el primero en 1959. A comienzos de la gestión de gobierno Frigerio caracterizaba la propuesta en sus libros "Las condiciones de la victoria" y "El desarrollo argentino y la comunidad americana". Sus tópicos eran:

a) El carácter científico en la formulación de la política económica como resultado de la elucidación de las leyes necesarias del desarrollo.

b) La necesidad del capital extranjero para favorecer el desarrollo de la industria de base -petróleo, siderurgia, petroquímica-

c) En relación con el punto anterior, la distinción entre capital extranjero que prolonga la dependencia y aquel que, por el contrario, permite superar el atraso.

d) La posibilidad de obtener los fondos necesarios por parte de los Estados Unidos como potencia hegemónica occidental, en el marco de su competencia con la Unión Soviética.

e) El nacionalismo de fines frente al nacionalismo de medios como instrumento para conseguir la efectiva - y no declamada - liberación nacional.

f) La existencia de una economía internacional atravesada por monopolios. La pequeña industria no puede convertirse en el motor del desarrollo.

g) La necesidad de aumentar la producción del campo a través de la industrialización y la oposición a dividir la tierra mediante una reforma agraria.

h) El impulso de la integración geográfica para combatir el gigantismo de la región pampeana.

i) Los fenómenos monetarios y la inflación son el reflejo de la oferta de bienes y por lo tanto, de la producción.

j) La participación del capital privado en la generación de riqueza. El estado debe orientar las actividades económicas y limitar su participación solo en sectores clave (Frigerio, 1959a) (Frigerio, 1959b)

Comparemos estas ideas con lo sostenido previamente por Arturo Frondizi. Aún en círculos extraacadémicos se conoce su oposición completa a la participación del capital extranjero en la industria petrolera expresada en el libro "Petróleo y Política" de 1954. No es una mención aislada y no es el único elemento disonante con las ideas desarrollistas. En los documentos emitidos por el Movimiento de Intransigencia Radical que lideraba Frondizi ${ }^{3}$ - donde tenía intervención principal en su redacción

\footnotetext{
${ }^{3}$ Nos referimos específicamente a la Declaración de Avellaneda de 1945, las Bases de Acción Política de 1947 -del Movimiento de Intransigencia Radical- y la plataforma electoral de 1951 de la UCR (Babini, 2006, págs. 44-64)
} 


\section{Angel Cerra}

- se expresaba no solo la oposición cerrada a la participación del capital extranjero; también se postulaba la nacionalización de todos los servicios públicos, el combate a los monopolios, el control democrático y popular de la economía, la necesidad de una reforma agraria "inmediata y profunda", la integración económica con los países vecinos, la exaltación del federalismo y el municipalismo. La claridad con que se expresan estas ideas permite descartar la participación de Frondizi en la elaboración del ideario desarrollista.

\section{La influencia de Prebisch y de los teóricos del desarrollo.}

Con frecuencia se ha intentado subsumir al desarrollismo frigerista dentro de la corriente estructuralista liderada por Prebisch desde la Comisión Económica para América Latina (CEPAL). En esa perspectiva, las ideas de Frigerio derivarían de esa usina con alguna disonancia no muy relevante. Sostendremos que: a) las diferencias entre el desarrollismo argentino y el estructuralismo que la CEPAL popularizara en las décadas de 1950 y 1960 son esenciales b) las coincidencias entre ambas posiciones se deben a la existencia de un tronco común a ellas de matriz leninista c) en escritos anteriores a la publicación del manifiesto "El desarrollo de América Latina y sus principales problemas", Frigerio y su grupo ya habían expresado buena parte de las ideas-fuerza que fueron reiteradas en 1959 y desarrolladas sistemáticamente después de la gestión de gobierno a partir de 1962.

Las coincidencias entre las ideas de Prebisch y el desarrollismo - no solo argentino, sino también internacional - son evidentes. La división del mundo en dos bloques, uno dominante -en la terminología de Prebisch, el centro- industrializado, rico y capaz de generar su propio desarrollo y otro, dependiente, exportador de materias primas, pobre e incapaz de realizar su crecimiento sostenido e integrado, es compartida entre ambas corrientes. Sin embargo, resulta necesario remarcar que buena parte de esa proposición - quizás no articulada en los mismos términos de Prebisch - es muy anterior a su formulación en 1949. La desigualdad en el comercio internacional y la necesidad de promover la industrialización local ya habían sido formuladas por Friedrich List en 1842. Los proteccionistas estadounidenses Henry Charles Carey y Simon Nelson Patten, replicaron poco después esos postulados. En las primeras décadas del siglo XX, el canadiense Harold Innis y el argentino Alejandro Bunge enfatizaron los efectos nocivos del librecambio para las economías de las naciones "jóvenes" (Lucchini \& Cerra, 2011)

Como señala Joseph Love, el rumano Mihail Mainolescu había sostenido en 1931 que la productividad de la industria era superior en una proporción de cuatro a uno en relación con la agricultura. Por lo tanto, era absolutamente necesario impulsar las actividades manufactureras (Love, 1996, págs. 392-393)

Por último, -last, but not least- detrás de las concepciones de la CEPAL y del frigerismo - como en tantas otras concepciones económicas y políticas- campea la sombra de Lenin. En su obra de 1917, "El imperialismo, fase superior del 


\section{Revisitando las fuentes ideológicas del desarrollismo: Rogelio Frigerio y el marxismo argentino}

capitalismo" el revolucionario bolchevique plantea la división del mundo entre países dominantes, colonias y semicolonias, estableciendo una clara relación de explotación entre las potencias capitalistas y el resto del mundo. Este y otros postulados leninistas informarán a las corrientes "desarrollistas" - incluida la de la CEPAL- de los años 50' y 60'.

Las diferencias entre ambas tradiciones son notables. Mientras la CEPAL recela de la participación del capital extranjero y trata de limitarlo al mínimo prefiriendo las fuentes públicas y abominando las privadas, el desarrollismo argentino propicia no sólo desde la teoría, sino también desde la práctica - la radicación de empresas extranjeras; en la corriente de Prebisch se concede gran importancia a la posibilidad de industrializar a partir del ahorro local, en tanto el frigerismo sostiene la necesidad de una gran inyección de capital en industria pesada y básica; los cepalinos insisten en la prioridad de una reforma agraria a la que taxativamente se opuso el socio de Frondizi y, finalmente, la CEPAL propiciaba la integración económica regional, mientras Rogelio Frigerio se oponía explícitamente a ella.

En conclusión: por un lado, las coincidencias entre las ideas de Prebisch y de Frigerio pueden explicarse por compartir un tronco común de ideas muy anterior a ambos pensadores. Por otro lado, las diferencias son tan evidentes que cualquier asimilación genética resulta poco fundamentada. Si a estas disonancias le agregamos la existencia de textos del grupo Frigerio anteriores a la publicación del manifiesto cepalino de 1949, deberíamos abandonar la ligazón vertical entre las ideas de la CEPAL en los años 50' y el desarrollismo local.

En trabajos anteriores, hemos sostenido que el desarrollismo argentino no era tributario de la corriente internacional englobada en el rótulo "teóricos del desarrollo". Brevemente expondremos que existen diferencias ideológicas notables, declaraciones taxativas de los supuestos influyentes que desestiman cualquier interacción y finalmente - como en el caso anterior - la presencia de escritos anteriores del frigerismo que permiten desestimar la influencia de estas ideas.

Los distintos autores que se citan - generalmente sin discriminar cada uno de sus aportes - muestran diferencias significativas con el pensamiento de Frigerio. Paul Rosenstein-Rodan, quién en 1943 postuló la necesidad de una gran cantidad de capital para superar el atraso de los países del Este de Europa, insistía en la necesidad de fraccionar la inversión entre distintos sectores. En el mismo sentido se manifestó años más tarde el estonio Ragmar Nurske quién perfeccionó la teoría del "crecimiento balanceado". La idea del crecimiento balanceado es completamente ajena al frigerismo, que insistía en concentrar la inversión en unos pocos sectores estratégicos y no dispersarla. La dispersión impediría el cambio de las estructuras productivas y la ruptura con el modelo anterior.

Por esta preferencia hacia la concentración del capital en unos pocos sectores, otros estudiosos han vinculado al desarrollismo argentino con Albert Hirschman, autor de la teoría del "crecimiento desequilibrado". Sin embargo, esta ligazón es imposible. Un primer reparo lo encontramos desde el análisis de las ideas. Nada aborrece más 


\section{Angel Cerra}

el frigerismo que la innovación a partir del desequilibrio y la apelación a la energía innovadora del empresario privado. La inversión desarrollista estaría conducida por un estado que fijaría prioridades y planearía la integración vertical. Nada quedaría librado a las "fuerzas creadoras" de capitalistas schumpeterianos; los empresarios, por un lado, contribuirían con el capital y disciplinarían a la mano de obra; los funcionarios estatales, por el otro, indicarían los sectores en los que se debe realizar la inversión, el lugar del país donde se radicaría, pactaría con cada compañía las cantidades de flujo previstas, los beneficios impositivos e impedirían el ingreso de productos competitivos desde el exterior (Cerra, 2008).

La segunda objeción es más concluyente: cuando Hirschman publica su libro en 1958, las ideas desarrollistas ya habían sido formuladas. Según la propia declaración del autor de "La estrategia del desarrollo económico" es temporalmente imposible que su obra influyera en el pensamiento de Frigerio (Cerra, 2010).

\section{La influencia de Alejandro Bunge}

De formación marxista, empresario, intelectual, político y con excelentes lazos con la iglesia católica, la figura de Frigerio es clave para la inteligibilidad de una evolución compleja y sujeta a tensión. Como intelectual, permanentemente estaba discutiendo y rediscutiendo sus ideas, con el evidente propósito de obtener el reconocimiento de sus pares. Pretendía buscar la verdad; es más: creía haberla encontrado y se mostraba dispuesto a confrontarla en términos científicos. Como ideólogo, debía estilizar y transformar esas ideas en palancas de acción. La reducción que implicaba ese proceso significaba sacrificar ciencia por política. Aunque se encontraba profundamente inclinado al poder, muchas veces Frigerio no pudo o no quiso simplificar su pensamiento para obtener repercusión popular o mayor permeabilidad en las clases propietarias. Quizás por ese motivo la ideología desarrollista quedó circunscripta a algunas élites: sus impulsores no se mostraron dispuestos a amputarla en su riqueza para convertirla en instrumento político. La contradicción resulta más evidente porque Rogelio Frigerio y sus colaboradores pretendían influir sobre los gobiernos o gobernar y contaban con medios económicos e inteligencia política para lograrlo. Desde el punto de vista moral, también estaban dispuestos a seguir lo que Max Weber llamó la "ética de resultados". Sin embargo, la pulsión por demostrar la superioridad de todo su andamiaje conceptual dificultó las concreciones políticas.

Habiendo examinado las que consideramos vías muertas en la explicación del proceso de construcción del desarrollismo argentino - el frondizismo, el estructuralismo de la CEPAL, los teóricos del desarrollo - expondremos nuestra propuesta sobre el modo en que se gestó efectivamente esa ideología.

En trabajos anteriores, hemos postulado una de las influencias más relevantes en el desarrollismo argentino: el economista Alejandro Bunge (Cerra, 2002, 2003, 2008, 2016, 2018). El influjo del creador de la Revista de Economía Argentina sobre los 


\section{Revisitando las fuentes ideológicas del desarrollismo: Rogelio Frigerio y el marxismo argentino}

frigeristas se desprende tanto de las propias declaraciones de los integrantes del grupo, como de las citas que el propio Frigerio realiza aludiendo a la herencia bungeana. Valoremos aún más esta circunstancia, dada la renuencia del socio de Frondizi a citar sus fuentes inspiradoras. Normalmente, no mencionaba más que a Adam Smith, David Ricardo, Karl Marx y Georg Wilhelm Friedrich Hegel suponemos que la mención al legado hegeliano era una estrategia para difuminar la "peligrosa" herencia marxista-.

Dado que la influencia de Alejandro Bunge en el desarrollismo argentino ya ha sido extensamente analizada con anterioridad, presentaremos brevemente los elementos que podrían haber impactado en el frigerismo:

a) Partiendo de los ensayos iniciales de Friedrich List, Bunge y Frigerio sostienen que el librecambio solo conduce al predominio de aquellos países que llevan la delantera en el desarrollo industrial.

b) Derivada del concepto anterior se postula la necesidad de utilizar el proteccionismo como instrumento de crecimiento manufacturero.

c) Ambos pensadores no rompen fundamentalmente con las bases teóricas de la economía clásica. Por distintas vías se arriba al desprecio de las cuestiones monetarias como explicativas del proceso económico: Bunge porque prefirió no incorporarlas en su análisis de la realidad y Frigerio, porque aun conociendo las propuestas del neoclasicismo y del keynesianismo, eligió refugiarse en los clásicos a los que considera objetivos.

d) Los dos destacan el rol de las relaciones económicas en la generación de solidaridades e identidades nacionales. Sólo un espacio productivo y comercial articulado puede generar una nación completa. Frigerio remite taxativamente a Bunge al afrontar la cuestión de la expansión económica en la consolidación de la nación. Es necesario, para contrarrestar la concentración de la población en la región pampeana, promover con criterio realista el crecimiento en otras áreas del país.

e) Tanto Bunge como Frigerio se muestran decididamente favorables a la participación del capital extranjero. Los fundamentos ideológicos básicos son distintos, pero la propuesta es común a los dos. Bunge niega la existencia del imperialismo en forma tácita o explícita. En el frigerismo, la relación es más compleja. Se reconoce la presencia del imperialismo, pero se observan intersticios que permitirían a los países subdesarrollados alcanzar la industrialización autónoma. Si el estado fija reglas de juego claras y se conduce con firmeza, la inversión extranjera es un mecanismo adecuado para acelerar el proceso de desarrollo.

f) Finalmente en los dos casos se sostiene que el estado debe tener un rol relevante en la vida económica, sin reemplazar a la iniciativa privada ni anular la presencia -si 


\section{Angel Cerra}

esto fuera posible- de los mecanismos de mercado. No se puede dejar en manos de los particulares la asignación de prioridades: el estado tiene en ese sentido un papel creador de producción y consumo.

\section{El legado marxista}

Examinaremos a continuación la vertiente marxista y su impacto en el desarrollismo argentino. Procederemos retrocediendo en el tiempo desde la primera enunciación en 1959 del credo frigerista - incompleta, pero conteniendo sus principales ideasfuerza- hasta el año 1947. Allí, el grupo Frigerio publicaba el libro - con autoría de Carlos Hojvat- Geografía Económico Social Argentina ¿Somos una Nación?4, donde se preanuncian los elementos esenciales del desarrollismo argentino

Desde finales de la década de 1930, Frigerio había constituido un grupo de estudio interesado en el examen de los problemas nacionales a partir de un análisis marxista ligado a la ortodoxia del Partido Comunista de la Unión Soviética (PCUS). El frigerismo estaba integrado por outsiders, marginales de los grandes espacios de poder y de la academia. Participaban en él intelectuales con un grado de formación elevado. Citemos algunos ejemplos: Ernesto Sábato, posteriormente famoso literato, era doctor en Física, perfeccionado en París y en el M.I.T.; Arturo Sábato, ostentaba un doctorado en Química; Jacobo Gringauz, fue un médico pionero de la homeopatía en la Argentina; Rogelio Frigerio, que no terminó sus estudios de Derecho, era una persona extremadamente culta. Lo único que posibilitó la existencia del grupo como verdadero think-tank era el aporte económico de varios de sus integrantes y amigos, entre ellos el propio Frigerio, Narciso Machinandiarena y los hermanos Aragón.

Ese grupo es el que publica en 1947. La influencia del comunismo ruso es profunda, tal como surge de la lectura de manuales contemporáneos editados por la Academia de Ciencias de la Unión de Repúblicas Socialistas Soviéticas (Konstantinov, 1956) Además, en trabajos anteriores, hemos señalado la copia casi textual del opúsculo de Stalin "El marxismo y la cuestión nacional” (Cerra, 2016, pág. 94)

Siguiendo la ortodoxia marxista, la publicación destacaba la necesidad del conocimiento científico de las leyes que guían la evolución humana:

"Para que nuestra misión histórica se realice con el menor entorpecimiento posible y la mayor seguridad de éxito, las fuerzas internas deberán alinear la política, la base social y la economía sobre los fundamentos que se deducen del análisis crítico y de los cuadros estadísticos. Las conclusiones del análisis y las cifras que lo fundamentan nos autorizan a formular las premisas que darán el sentido general de la política nacional". (Hojvat, 1947)

${ }^{4}$ La vinculación entre la publicación y el grupo frigerista es postulada por Carlos Altamirano (Altamirano, 1998) y reconocida por los integrantes del think tank que acompañaban al futuro socio político de Frondizi (Morando, 2013, págs. 22-32) 


\section{Revisitando las fuentes ideológicas del desarrollismo: Rogelio Frigerio y el marxismo argentino}

Obsérvese la insistencia en el conocimiento científico para dotar a la acción de gobierno de un rumbo certero. En fechas posteriores, Rogelio Frigerio sostendría:

"Y así como las leyes económicas son tendenciales, son también objetivas, esto es, se verifican en la realidad con independencia de la voluntad humana, voluntad que no puede interferir ante el hecho de que tal causa producirá tal efecto. Pero son leyes cuyo conocimiento es indispensable para que esa voluntad ni se frustre navegando contra la corriente ni quede inerme, esto es, para que sea posible una orientación consciente del proceso económico" (Frigerio, 1979, pág. 14)

El economicismo, o sea la derivación de la realidad social y política de la infraestructura material, tan cara al pensamiento desarrollista, probablemente tenga origen en el marxismo vulgar a través de la versión difundida por los manuales soviéticos citados 5 . De la misma manera, el grupo frigerista manejaba hacia 1947 en clave leninista- la división entre países desarrollados y subdesarrollados y el fenómeno de la dependencia6.

Debemos volver al grupo proto desarrollista inicial para encontrar otros elementos esenciales en el pensamiento de Frigerio. El primero de ellos es el papel del capital extranjero como elemento modernizador. Ese fue el rol que tuvo el capital británico: "Para alcanzar la independencia institucional que hoy tenemos, estuvimos conminados a aceptar las relaciones económicas sociales y políticas del siglo XIX. El capitalismo inglés dio nueva batalla al feudalismo en tierras del Plata" (Hojvat, 1947, pág. 18)

El desarrollo se produjo con la presencia del capital extranjero que lo impulsa y/o permite ${ }^{7}$.Obsérvese como aparece aquí una variante de lo que acertadamente

\footnotetext{
5 Afirma una publicación de la época: "las relaciones económicas son primarias: existen y se desarrollan independientemente de la conciencia y la voluntad de los hombres y determinan su conciencia y su voluntad. Las formas político-jurídicas y las relaciones ideológicas reflejan las relaciones de producción, que constituyen la base de la sociedad" (Konstantinov, 1956, pág. 99)

6“Por su atraso y escasa potencia industrial y financiera, los países económicamente dependientes pueden ser clasificados según tres grados de dependencia y atraso económico: 1o Países económicamente dependientes, pero de relativa independencia institucional y política. Tal es el caso de nuestro país, Australia, Canadá, Suecia ... 20 Países semicoloniales, con cierto grado de desenvolvimiento político e institucional ... 3ำ Países coloniales, económica, institucional y políticamente dominados ... Los países de gran desarrollo económico, que representan el núcleo esencial de la etapa monopolista de la economía privada, tienden a la dominación económica y por consiguiente, presionan sobre las estructuras económico-sociales de los países atrasados y dependientes, cualquiera sea el grado de dependencia y del atraso" (Hojvat, 1947, págs. 96-97)

7"Fuimos un país de ganadería; Inglaterra nos llevó después hacia la explotación agrícola y salimos hacia el exterior. Esta salida hacia el exterior nos llevó por el camino de la industrialización. Cualquiera haya sido la causa -la competencia entre los países más industrializados o el incremento de las relaciones económicas de las fuerzas internas- lo cierto es que se crearon en el país formas económicas modernas aptas para mantener relaciones comerciales y financieras con el resto del mundo. ... Junto a las antiguas formas económicas surgidas de nuestra dependencia de Inglaterra, se originaron y crecieron formas modernas que predominan interiormente y mantienen la economía del país integrando la economía mundial con factores nuevos, capaces de ulteriores desarrollos" (Hojvat, 1947, pág. 33 y 37)
} 


\section{Angel Cerra}

Arturo Jauretche denominó "proceso dialéctico a la vaselina" (Jauretche, 1984, pág. 22) En definitiva, se va a poder pasar sin mayores sobresaltos de la colonia al dominio inglés; de la hegemonía británica al dominio estadounidense y de éste a la soberanía económica plena. El duro tutelaje de la rubia Albión es el que permite el tránsito a la industrialización. El carácter necesario e impersonal del cambio, se traduce en la frecuente utilización de frases reflejas y de la existencia de agentes etéreos: formas modernas, transformaciones, economía mundial, entre otros.

Por supuesto que la participación inglesa tenía su costo: la dependencia. Sin embargo, es claro el carácter progresivo del capital extranjero.

La necesidad de apelar a los capitales extranjeros surge de otro elemento prefigurado en los escritos de 1947. La economía mundial -en sus versiones, capitalista o comunista- se hallaba controlada por los monopolios. Las industrias que dominaban a nivel internacional se encontraban fuertemente concentradas (Hojvat, 1947, págs. 99-104) Por ese motivo, las estrategias gradualistas que pregonan el desarrollo manufacturero a través de la reinversión del ahorro interno son irrealizables. Solamente se puede jugar en los sectores altamente concentrados realizando inversiones cuantiosas que sólo pueden provenir del capital extranjero. Al finalizar la Segunda Guerra Mundial, la coyuntura internacional parecía favorable. La aparición de la Unión Soviética como contendiente de británicos y estadounidenses abre una brecha auspiciosa. Los futuros desarrollistas sostenían en la inmediata posguerra que la coexistencia pacífica entre el bloque occidental y el comunista, exigiría a los Estados Unidos la realización de esfuerzos para evitar la huida de los estados semicoloniales al lado soviético (Hojvat, 1947, pág. 142)

Preanunciase un clásico del desarrollismo. El escenario internacional abre las posibilidades de jugar con el enfrentamiento Este-Oeste para lograr la emancipación nacional. Aunque el corazón de los autores se ubique cercano a la Unión Soviética, le conceden a los Estados Unidos la revisión de su postura como instrumento adecuado para conservar la hegemonía en el bloque occidental.

En resumen, en fechas tan tempranas como 1947, se encontraban claramente explicitados los supuestos constitutivos del desarrollismo argentino: la existencia de leyes económicas necesarias que guían el proceso histórico, incluyendo la superestructura política y cultural; la presencia de una economía mundial monopólica, donde la pequeña producción desaparecería inevitablemente; el rol del capital extranjero como modernizador y creador de dependencia, si no se lo conduce de manera adecuada; la división del mundo entre países industrializados y dependientes -en lenguaje leninista: semicolonias y colonias- y, por último, la coexistencia pacífica, que demandará a los Estados Unidos esfuerzos financieros para promover el desarrollo de los países subordinados y evitar así su fuga hacia el comunismo.

Hemos señalado los antecedentes - muy anteriores a la sociedad política con Frondizi, a la publicación del manifiesto de Raúl Prebisch y a la difusión de las ideas de los teóricos del desarrollo -; permiten establecer una línea clara que une al think tank frigerista de la década de 1940 con la producción desarrollista de finales de los 


\section{Revisitando las fuentes ideológicas del desarrollismo: Rogelio Frigerio y el marxismo argentino}

50’. A continuación, retrocederemos aún más en el tiempo, buscando las raíces de esas ideas.

\section{El joven Frigerio}

A pesar del tiempo transcurrido desde la presidencia de Arturo Frondizi y de la desaparición física de los dirigentes desarrollistas, la temprana participación del joven Frigerio en el comunismo local aún es admitida a regañadientes por sus biógrafos y disminuida en su compromiso. Llama la atención esta decisión por parte de intelectuales y políticos habiendo desaparecido la causa del ocultamiento: el veto de las Fuerzas Armadas y de los sectores afines al bloque occidental que jaquearon la gestión desarrollista entre 1958 y 1962 bajo el pretexto de la supuesta pertenencia comunista de sus principales dirigentes.

Un examen de las fuentes de la época, específicamente de la revista Claridad, permite observar que la vinculación entre Frigerio y el comunismo local fue más profunda y menos eventual de lo que se ha escrito. Y que el enfrentamiento con las autoridades del PCA y el distanciamiento de sus ámbitos de influencia, no fue ni tan enérgico, ni tan temprano.

Constatar la prolongada cercanía de Frigerio a este sector en sus años de formación, nos obliga a profundizar el examen de la influencia que sobre sus ideas tendrán otros exponentes notables del marxismo vernáculo, como Ernesto Giudici.

Hay coincidencia entre distintos autores sobre la vinculación de Rogelio Frigerio con la agrupación estudiantil Insurrexit durante la década de 1930. En su calidad de alumno de la Facultad de Derecho de la Universidad de Buenos Aires, el creador del desarrollismo ingresó en esa organización y fue su Secretario General en 1934. Si bien aparentaba independencia respecto del Partido Comunista Argentino y de la Federación Juvenil Comunista, Insurrexit era una agrupación que dependía de las directivas de esas agrupaciones.

El modo en que la corriente universitaria estaba vinculada con el PCA puede esclarecerse por varias vías. Una de ellas se relaciona con la discusión sobre el significado de la Reforma Universitaria en el II Congreso de la Federación Universitaria Argentina (1932). Allí, Insurrexit -liderada por Héctor Agosti, con quién Frigerio consolidará una fuerte amistad, y apadrinada por Aníbal Ponceaplicó la tesis de la "lucha clase contra clase" al análisis de la Reforma del 18'. Con ese cristal, calificó al movimiento reformista como "pequeño burgués" desdeñando su concepción latinoamericanista, tan extendida en la región a través de los trabajos de Vasconcelos, Mella y Haya de la Torre. Recordemos que la estrategia "clase contra clase" había sido propuesta en 1928 por el VI Congreso de la III Internacional y adoptada sumisamente por el PCA. A partir de esa decisión, se exaltaba la necesidad de luchar contra el liberalismo y el fascismo y se proclamaba que el socialismo moderado debía ser considerado el principal enemigo a batir. 
Para expresarlo más sencillamente: en sus etapas formativas juveniles, Frigerio integraba un grupo estudiantil - del que fue su Secretario General en 1934 refractario al latino americanismo. La postura evolucionista y europeizante fue la norma en el PCA, con las excepciones notables de Rodolfo Puiggrós (Puiggrós, 1949 -Primera Edición 1940-) y Juan José Real. Ambos fueron los historiadores oficiales del partido y expulsados por sus heterodoxias con posterioridad

Si bien Frigerio reconoció su participación en Insurrexit, siempre negó haberse afiliado al PCA. Según Isidoro Gilbert, no fue tan tajante respecto a su pertenencia a la Federación Juvenil Comunista (FJC) (Gilbert, 2009, pág. 30). La agrupación universitaria se disolvió en 1935, lo que favorecería en principio la verosimilitud de un acercamiento eventual y poco profundo con el PCA, su dirigencia y sus ideólogos. Sin embargo, existen elementos que debilitan la hipótesis del "paso fugaz juvenil". Uno de los más evidentes y extrañamente omitido por los historiadores es la producción escrita del propio Frigerio en la Revista Claridad ${ }^{8}$. A partir de la revisión de esta publicación de izquierda durante los años 30' hemos hallado tres artículos. El primero de ellos, de agosto de 1936, es un pedido por la libertad de su amigo Héctor Agosti ${ }^{9}$ (Frigerio, 1936). En 1937, - anotemos que Insurrexit se disolvió en 1935 - publicaba un segundo artículo donde defendía la posición oficial del PCA: se proponía la formación de un frente popular que englobara a otras fuerzas pequeñoburguesas ${ }^{10}$. Invitaba a los radicales - en realidad exigía, como acostumbraba a hacer Frigerio - a sumarse a una amplia coalición anti-oligárquica. Ante la perspectiva de las futuras elecciones, sostenía:

"Así es como el partido mayoritario, al escamotear a la masa la verdadera solución popular, deba presentarse a sí misma con fuerzas capaces de imponer el triunfo. Y mientras la experiencia se empecina en demostrar lo contrario, el radicalismo fomenta en el pueblo esperanzas malsanas en un posible regeneramiento (sic) místico de los eternos estafadores de su voluntad, impidiendo la creación del Frente Democrático'" [que integrarían junto con los radicales y socialistas, los comunistas, A.C.] (Frigerio, 1937)

\footnotetext{
${ }^{8}$ La primera mención de estas intervenciones de Frigerio proviene del panfleto "El libro rojo de Rogelio Frigerio", compilado de informaciones y rumores inventados por los servicios de inteligencia de las Fuerzas Armadas y publicado en 1962 en Montevideo. Allí se mencionan dos participaciones: una en la que exalta el materialismo histórico en un artículo sobre Robert Owen de 1938 y otra de 1936, donde pide la libertad de su amigo Héctor Agosti. En el libro de Morando, se transcribe la cita del año 1938, sin aclarar que proviene de segunda mano, es decir, que es copiada del panfleto (Ortiz, 1962) (Morando, 2013)

${ }^{9}$ La amistad de Frigerio con Agosti sobrevivió a las vicisitudes de la vida política argentina. El primero cuidó de los ingresos del segundo otorgándole un lugar de colaborador anónimo en el diario Clarín.

10 El VII Congreso Mundial de la Internacional Socialista de agosto de 1935 estableció que era imperioso aliarse con las fuerzas partidarias pequeño-burguesas para luchar contra el fascismo. En la Argentina esa alianza incluía a socialistas y radicales.
} 


\section{Revisitando las fuentes ideológicas del desarrollismo: Rogelio Frigerio y el marxismo argentino}

Se observa que en 1937 Frigerio se sentía plenamente identificado con el Partido. En el mismo artículo, exaltaba la movilización de 200.000 personas conmovidas por el líder comunista, Orestes Ghioldi. Finalmente, hacia 1938, repetía su participación en Claridad con una nota sobre el socialismo utópico de Robert Owen. Exaltaba la coherencia de Marx y Engels y al socialismo científico, como instrumento para comprender y transformar la realidad (Frigerio, 1938)

Observamos entonces que la producción del "tapir" en Claridad nos hace dudar de su enfrentamiento con el Partido Comunista, por haberse inclinado tempranamente-según sus propias palabras - hacia una posición "nacional". Esa "posición nacional", contraria a la del Partido Comunista Argentino, tampoco parecería la de aquellos que acompañaron a Frigerio en Insurrexit, en su trayectoria de los grupos de estudio en los años 1930 y 1940 y en la primera etapa de la revista Qué de 1946-1947. Así, Ernesto y Arturo Sábato, militaron en la Federación Juvenil Comunista y en Insurrexit ${ }^{11}$. También lo hicieron, en una u otra organización personas muy cercanas a Frigerio como Baltasar Jaramillo y Narciso Machinandiarena, Bernardo Sofovich, el empresario Eduardo Aragón, Carlos Hojvat y Jacobo Gringauz (Longoni, 2006). Con varios de ellos, compartiría emprendimientos empresarios, como los del Hotel Alfar en Mar del Plata -con pinturas de Castagnino, afiliado al PCA- y una clínica homeopática que inauguró en 1954 con Carlos Hojvat.

Sin embargo, el propio Frigerio siempre se ocupó de presentar la ruptura con el PCA como temprana y completa. Y la adopción de una posición nacional, cercana al peronismo, hacia 1946-47. Su supuesta simpatía por este movimiento, es lo que habría provocado el prematuro alejamiento de la revista "Qué sucedió en 7 días", donde compartía la dirección con Baltasar Jaramillo (Anónimo, 1983, pág. 18)

La afirmación es incomprobable - Jaramillo se suicidó pocos años después y no puede corroborarla - e improbable. Dos elementos contribuyen a subrayar la improbabilidad del carácter nacional -o filoperonista- de Frigerio en la década de 1940. En primer lugar, tenemos la opinión de intelectuales como Arturo Jauretche que conocieron desde su juventud al creador del desarrollismo argentino. El autor del "Manual de zonceras argentinas" compartió reuniones sociales con el grupo frigerista desde la década de 1930. Polemizando con Frigerio, en 1946 lo ubica claramente en la "otra vereda" junto a la Unión Democrática y el comunismo vernáculo. (Jauretche, 1984, pág. 27)

En segundo lugar, el citado trabajo "Geografía Económico-Social Argentina ¿Somos una Nación?" muestra un stalinismo rústico. Como ya expusimos, el libro anticipó tópicos importantes del desarrollismo y se muestra fuertemente marcado por la

\footnotetext{
11 Frigerio - negando otra vez a la entrevistadora su pertenencia al comunismo - relata los años de su militancia en Insurrexit en estos términos: "Era una vida muy dura; después vinieron cosas peores, aunque también nosotros conocimos la picana eléctrica, la Sección Especial. Nos perseguían y estábamos inseguros, mal alimentados. Pero teníamos un increíble fervor, nos consumía el afán de saber, de capacitarnos para ejercer el poder" (Constenla, 2011)
} 
poco sofisticada ideología del dictador georgiano, tal como era propalada por el PCUS en esos años.

En conclusión, es imposible establecer en qué fechas Rogelio Frigerio se aleja del comunismo argentino (al que, según él, nunca perteneció). Sí podemos afirmar que hasta 1937 era el portavoz de sus ideas en la Revista Claridad, que testigos de la época lo ubican en la Unión Democrática hacia 1946 y que la publicación colectiva de 1947 responde casi por completo a la ideología oficial del Partido Comunista Argentino. En estas manifestaciones no se vislumbra el componente nacional o filoperonista.

¿Por qué insistimos en la permanencia de Frigerio en el "espacio cultural comunista", aún en la década de 1940? Porque esa permanencia nos permite incorporar otras influencias que no han sido analizadas por la historiografía. Específicamente, examinaremos los aportes del brillante Ernesto Giudici y del opaco Victorio Codovilla en la invención del desarrollismo argentino.

\section{La revista Claridad, Ernesto Giudici y Rogelio Frigerio}

La revista Claridad se consolidó en la década de 1930 como un medio abierto a distintas expresiones de izquierda de Europa, Latinoamérica y Europa. Combinaba artículos con un cierto contenido teórico con otras colaboraciones que tenían un carácter claramente político.

Coincidimos con Ferreira de Cassone en caracterizar a la publicación como un espacio amplio. Dirigida por el socialista Antonio Zamora, en sus páginas se encuentra reflejado un amplio espectro de opiniones de izquierda, incluyendo a socialistas, comunistas, anarquistas, trotskistas y al aprismo ${ }^{12}$. En algunas coyunturas, se daba espacio a vertientes democráticas-liberales, como en el momento de la formación de los frentes populares en América Latina. Claridad se mostraba alejada de la ortodoxia del Partido Comunista, pero le concedía espacios para la difusión de sus posiciones y coincidía en su admiración de la Unión Soviética tanto por su papel como potencia mundial como por su importancia cultural e ideológica en la consolidación del marxismo. La presencia precoz de Frigerio en la revista a la edad de 21 años seguramente se debe a su actuación en Insurrexit y, por lo tanto, a la intercesión del PCA.

El caso de Ernesto Giudici es muy distinto. Nacido en 1907, era un estudiante brillante en la Facultad de Medicina de la Universidad de Buenos Aires que no llegó a recibir el título de médico por su oposición directa a la dictadura de José Félix Uriburu. Pertenecía originalmente al Partido Socialista, de donde es expulsado en 1934 por sus tendencias clasistas. En esa misma fecha, se incorporaba al Partido Comunista. En 1932, en el citado II Congreso de la Federación Universitaria

\footnotetext{
${ }^{12}$ La presencia del aprismo debe destacarse. Además de las numerosas noticias sobre la evolución del APRA en la vida política del Perú, el pensamiento de Haya de la Torre fue publicado en veintiocho oportunidades (Ferreira de Cassone, 2005, pág. 403)
} 


\section{Revisitando las fuentes ideológicas del desarrollismo: Rogelio Frigerio y el marxismo argentino}

Argentina defendió la posición que revalorizaba la Reforma del 18' enfrentando a Insurrexit. A diferencia de Héctor Agosti, que en los años 30' debía su influencia a la tutela de Aníbal Ponce - después sí adquiriría vuelo propio - Giudici era más independiente y poseía cierto juego autónomo dentro de estructuras partidarias que se caracterizaban por su rigidez. Su peso derivaba tanto de su lucha personal, como de su actividad autoral en distintas publicaciones de izquierda.

La revista Claridad recibía y editaba con frecuencia sus colaboraciones ${ }^{13}$, siendo durante la década de 1930 uno de sus principales escritores. Esta circunstancia es muy importante. Al conocimiento hipotético que el joven Rogelio Frigerio tendría de los escritos de Ernesto Giudici por su pertenencia al "espacio comunista", debemos agregar su segura lectura de Claridad. Resulta obvio, dado que el propio creador del desarrollismo publicaba en la revista.

Durante los años 30' Ernesto Giudici se caracterizó por su prédica antinazi desde el marxismo. En 1938, mostraba la penetración nazi en América con su libro "Hitler conquista América". Sin embargo, durante el período de vigencia del pacto Ribbentrop-Molotov publicó una obra donde denuncia la presencia ominosa del capital inglés en la Argentina: Imperialismo inglés y liberación nacional-La Argentina y la Guerra. Más allá de cierta ruptura con la producción anterior que se centraba en la crítica demoledora hacia el nazismo, la lectura del libro nos permite vislumbrar ciertos elementos que serán esenciales en la concepción desarrollista. Esos elementos pueden atribuirse al pensamiento propio de Giudici o a la existencia de tradiciones marxistas que lo anteceden. Ambos supuestos nos permiten ubicar al desarrollismo fuera de las corrientes de los teóricos del desarrollo o cepalinas y resaltar su pertenencia al espacio intelectual argentino. ${ }^{14}$

\section{El capital extranjero}

Uno de los puntos nodales de la ideología desarrollista es la necesidad de recurrir al capital extranjero para promover el cambio de estructuras de la economía argentina. Por eso, su propuesta - implementada durante la gestión de gobierno entre 1958 y 1962- de favorecer las inversiones vinculadas con las ramas básicas de la industria, como el sector petrolero. La idea predominante es que el capital externo no es bueno o malo per se, sino que su carácter se deriva del uso que se realiza de él. En 1940, Ernesto Giudici se refería al problema del capital extranjero en términos similares. Polemizando con los nacionalistas rosistas sostenía:

"El punto de partida [de los nacionalistas rosistas] es contrario, inverso, antagónico al nuestro. Nuestra acción -dijimos- es una acción de lo porvenir que arranca del presente y del presente

\footnotetext{
13 Giudici aportó veintiún artículos para Claridad, generalmente con una extensión que triplicaba lo habitual en la revista (Ferreira de Cassone, 2005, pág. 400).

14 También se consolida nuestra idea del carácter temprano de la ideología, polemizando de ese modo con la interpretación de Celia Szuterman (Szuterman, 1998)
} 
capitalista argentino, presente en el cual aún seguimos necesitando de las inversiones del capital extranjero, aunque el Estado Nacional que debemos formar controle esas inversiones en todos sus aspectos, para que inversión capitalista no signifique como hasta aquí, mayor sujeción, sino creación de industrias y trabajo en el perfil de la Nueva Argentina que está surgiendo de las entrañas mismas de la Argentina agropecuaria que Inglaterra modeló en el marco de sus intereses ${ }^{15 " ~[n e g r i t a s ~ a n ̃ a d i d a s, ~ A . C .] ~}$ (Giudici, 1940, págs. 8-9)

La idea es básicamente la misma: el capital extranjero es un elemento de progreso necesario, siempre que se lo use con un sentido nacional, es decir, para favorecer el desarrollo industrial argentino. Al servicio de la Argentina agropecuaria -Giudici- o pastoril -tal como gustaba denominarla Frigerio en homenaje a Alejandro Bunge-, ese capital conlleva un aumento de la dependencia.

Llama la atención la coincidencia y nos debería inclinar a pensar en una filiación genética entre lo expuesto por Giudici y el desarrollismo argentino. Sin embargo, debemos anotar que el intelectual comunista no era un exponente aislado de estas ideas. Por la misma época, el aprismo - cuantitativamente la corriente política más representada en los artículos de Claridad - proponía un camino similar ${ }^{16}$. Así se expresaba en 1931 el Programa Mínimo del Partido Aprista Peruano:

\begin{abstract}
"El capital extranjero representa en nuestro país técnica, porque el capital extranjero es el que trae máquina. Nosotros no somos pueblo industrial porque no hemos creado la máquina; solamente manejamos la máquina que nos viene de fuera. Pues bien, el capitalismo extranjero que es inevitable en países como el nuestro, cumple su etapa; lo importante es que la cumpla bajo el control de un Estado que represente verdaderamente a la mayoría de la nación que está interesada en no ser absorbida" [negritas añadidas, A.C] (Haya de la Torre, 1931)
\end{abstract}

Las coincidencias son significativas. Sin embargo, no deberíamos sorprendernos, porque los tres autores (Frigerio, Giudici y Haya de la Torre) compartieron una lectura común - la obra de Lenin - y vivieron intensamente el devenir de la experiencia soviética. Son innumerables las ocasiones en las que el líder bolchevique remarca la necesidad de recurrir al capital extranjero, aún en las peores condiciones. Por ejemplo:

"Todas las posibilidades de la construcción socialista dependen de que, durante un determinado período de transición, logremos defender nuestra independencia económica interior, pagando

\footnotetext{
15 Obsérvese la presencia del tópico marxista respecto al modo en que el nuevo orden dominante va gestando las contradicciones que crecen en su interior y terminarán con él. La idea es repetida en el citado manifiesto frigerista de 1947 y en escritos muy posteriores del propio Frigerio (Frigerio, 1979).

16 La filiación entre aprismo y desarrollismo fue postulada, entre otros por Marcelo Rougier (Rougier, 2016, pág. 44).
} 


\section{Revisitando las fuentes ideológicas del desarrollismo: Rogelio Frigerio y el marxismo argentino}

cierto tributo al capital extranjero" [negritas añadidas, A.C] Citado por (Real, 1968, pág. 39)

En el discurso del 6 de diciembre de 1920, Lenin sostenía:

Con anterioridad al Congreso de los Soviets recibirán ustedes un resumen de 600 páginas: es el plan de electrificación de Rusia. Ha sido elaborado por los mejores agrónomos e ingenieros. No podemos acelerar su realización sin ayuda de capitales y medios de producción extranjeros [negritas añadidas, A.C] (Real, 1968, pág. 47)

Ante el pedido de un campesino anónimo de "no vender nuestra querida Rusia a los concesionarios" extranjeros, aseveraba:

Indudablemente prestamos toda la atención a tales declaraciones, pero debemos decir que no se trata en absoluto de vender Rusia a los capitalistas, sino de concesiones; por lo demás en cada tratado sobre concesiones se estipula un determinado plazo, ciertas condiciones y está rodeado de todas las garantías,(...) Nada tienen que ver con la venta de Rusia; constituyen cierta concesión económica a los capitalistas, con el objeto de lograr la posibilidad de adquirir lo más rápido posible las maquinarias y locomotoras indispensables, sin las que no podemos realizar la reconstrucción de nuestra economía [negritas añadidas, A.C] (Real, 1968, pág. 67)

Para quienes estamos familiarizados con la narrativa frigerista, es sencillo reconocer ciertos elementos que la informan: el carácter necesario y progresivo del capital foráneo para cambiar las estructuras internas, expresado en la transparente frase de Lenin "defender nuestra independencia económica interior, pagando cierto tributo al capital extranjero" y la necesidad de apurar los ritmos de crecimiento productivo mediante la aplicación de inyecciones de capital provenientes del exterior.

Podemos retroceder aún más en el tiempo en esta aventura intelectual. El propio Marx no tenía dudas sobre la superioridad del capital inglés y el carácter necesario y progresivo de su intervención. Al tiempo que sumía en la pobreza a las masas campesinas de la India, preparaba las condiciones para su liberación:

Inglaterra tiene que cumplir en la India una doble misión destructora por un lado y regeneradora por otro. Tiene que destruir la vieja sociedad asiática y sentar las bases materiales de la sociedad occidental en Asia (...) Todo cuanto se vea obligada a hacer en la India la burguesía inglesa no emancipará a las masas populares ni mejorará sustancialmente su condición social, pues tanto lo uno como lo otro, no sólo dependen del desarrollo de las fuerzas productivas, sino de su apropiación por el pueblo. Pero lo que sí no dejará de hacer la burguesía es sentar las premisas materiales 
necesarias para la realización de ambas empresas. [negritas añadidas, A.C.] (Marx, 1853)

Más allá de profetizar la segura caída del capitalismo por la exacerbación de las tensiones de clase, podemos rescatar la estrecha relación entre inversión externa y progreso material, reiteradas por los cuatro autores citados precedentemente

Relacionada con la cuestión, vemos anunciada en Giudici la disyuntiva que recogerá el frigerismo en la oposición entre "nacionalismo de medios" y "nacionalismo de fines":

"Distingamos siempre, pues, entre apariencia y realidad. Sepamos ver lo que es nacionalismo opuesto a la liberación nacional, pese a sus posturas nacionalistas y lo que es liberación nacional efectiva, pese a su apariencia en contrario." (Giudici, 1940, pág. 13)

"Liberación nacional no es aislamiento antiextranjero, sino coincidencia con lo más progresista del mundo contra lo más reaccionario que, dentro de cada país, halla apoyo en los sectores más retrógrados" (Giudici, 1940, pág. 11)

Otra coincidencia notable que debería hacernos pensar en la influencia de Giudici sobre el pensamiento de Frigerio se expresa en la caracterización de la Argentina como país capitalista con status semicolonial. Como el creador del desarrollismo, Giudici se negaba a englobar a nuestro país en el contexto latinoamericano, remarcaba su originalidad y cuestionaba la necesidad de realizar una reforma agraria, ya que sus estructuras no eran feudales, ni semifeudales: eran capitalistas ${ }^{17}$. Son conocidas la clara postura de Frigerio caracterizando a nuestro país como plenamente capitalista y su oposición a la reforma agraria. La posición desarrollista en torno a la cuestión de la de la tierra es adversa a la pequeña propiedad, que resultaría improductiva frente a la gran explotación agrícola. Lo importante es la modernización del agro y la incorporación de tecnología en el campo, tal como lo mostraba el experimento soviético con los koljoses y sovjoses ${ }^{18}$ (Academia de Ciencias de la URSS - Instituto de Economía, 1957 -Primera Edición en español 1955). La pequeña propiedad era un factor retardatario del progreso, así como la

\footnotetext{
17 “La liberación nacional implica en los países dependientes o semidependientes una revolución fundamentalmente agraria, pero como dijimos, eso varía, en grado o intensidad, en cada país. En la Argentina, los problemas del campo deben irse solucionando juntamente con otros problemas que afectan a la industria y a nuestro desarrollo político, pues la Argentina no es un país semifeudal, sino un país capitalista sometido financieramente al imperialismo" [negritas añadidas A.C.] (Giudici, 1940, pág. 23) La polémica en el espacio comunista era intensa. Para la misma época, Rodolfo Puiggrós insistía en el carácter feudal de la Argentina (Puiggrós, 1949 -Primera Edición 1940-) (Acha, 2006)

${ }_{18} \mathrm{Al}$ producirse la Revolución Soviética, luego de la etapa conocida como comunismo de guerra, el gobierno de Lenin promovió la unificación de las pequeñas explotaciones campesinas en granjas colectivas llamadas koljos, gestionadas en principio por los propios campesinos con asesoramiento del estado. Posteriormente se crearon las granjas estatales denominadas sovjos, consideradas preferibles por la posibilidad de aplicar métodos científicos masivos a la explotación agrícola. Ambas partían del supuesto de las insuficiencias económicas de la pequeña producción campesina.
} 


\section{Revisitando las fuentes ideológicas del desarrollismo: Rogelio Frigerio y el marxismo argentino}

pequeña industria no podía oponerse a la eficiencia de la gran empresa manufacturera.

\section{Directo de Moscú: Vittorio Codovilla}

La contracara de Ernesto Giudici dentro del Partido Comunista fue Vittorio Codovilla. Más allá de hechos oscuros en su biografía como la eventual participación en el asesinato de Trotsky, su actuación en el PCA se caracterizó por el verticalismo hacia el PCUS y la persecución ideológica de aquellos intelectuales y militantes comunistas que se apartaban un centímetro de la ortodoxia. Su producción escrita, entonces, es la decodificación literal de las órdenes emanadas por Moscú. Mientras Ernesto Giudici encarnaba el vuelo intelectual de un pensador relativamente autónomo y serio, Codovilla expresaba el "sentido común" stalinista.

Será - para Frigerio - otra fuente más de aceptación del capital extranjero como motor del desarrollo. En la particular coyuntura del fin de la Segunda Guerra Mundial de 1945, Vittorio Codovilla propone:

"Mientras nos oponemos tenazmente a la existencia de los trust y monopolios extranjeros y nacionales, que estrangulan la economía nacional, no nos oponemos, en cambio, a que venga el capital extranjero (sobre la base de un interés razonable) al desarrollo de nuestra industria y de nuestros medios de transporte. Nos proponemos desarrollar la economía de nuestro país de un modo uniforme y progresista. Para acelerar ese proceso se necesitan capitales. Sabemos que ninguna nación de relativamente corta existencia, deseosa de desarrollar rápidamente su industria y explotar racionalmente su industria, ha podido prescindir de los capitales extranjeros" [negritas añadidas, A.C.] (Codovilla, 1945a, pág. 169)

En boca de la ortodoxia más ligada a Moscú, se vuelve a subrayar la necesidad de impulsar el crecimiento de nuestros países a partir del concurso del capital extranjero. En relación con la posibilidad de desarrollarse con la contribución de las principales potencias occidentales, Codovilla se muestra optimista y anticipa un tópico desarrollista:

"Las condiciones internacionales de cooperación entre los grandes países capitalistas y entre éstos y la Unión Soviética para la creación de un mundo mejor, indican que Estados Unidos e Inglaterra han de llegar a un acuerdo con respecto a la política económica a seguir en América Latina, a fin de contribuir al desarrollo económico, político y social de nuestros países en un sentido progresista. (...) Ese acuerdo deberá basarse en la cooperación de aquellas grandes potencias con los gobiernos democráticos y progresistas de América Latina para el cumplimiento de un programa común que 
al mismo tiempo que brinde un mercado diez o veinte veces superior al actual para sus capitales, sus maquinarias y sus productos industriales contribuyan al desarrollo independiente de la economía de esos países y les permita, en pocos años, liquidar el atraso en que vienen arrastrándose desde hace décadas" [negritas añadidas, A.C] (Codovilla, 1945b, pág. 15)

La postura resultó claramente circunstancial y se explica por la tendencia browderista en América Latina, que pudo sobrevivir dentro del comunismo internacional durante el corto tiempo en que funcionó la alianza entre Estados Unidos y la Unión Soviética para derrotar al nazismo. Esta salvedad no invalida lo más importante. Es posible construir una línea explicativa perfectamente coherente que nos permite encontrar el corazón del ideario desarrollista en fechas tempranas. Esta línea surge del contacto de Frigerio con el comunismo internacional, a través de sus distintas expresiones locales -Giudici y Codovilla, entre otras- y de movimientos latinoamericanos coetáneos como el aprismo. Los antecedentes referencian a los escritos de Lenin en torno a la necesidad de contar con capitales externos y del propio Marx en cuanto a su carácter progresivo - aun conllevando el germen de la exacerbación de las tensiones sociales y la ruina del sistema capitalista. Por la vía de los escritos y discursos que informaban el espacio de izquierda en la Argentina de los años 30' y 40' encontramos otros elementos formativos importantes: la insistencia sobre el carácter capitalista - y no feudal o semifeudaldel campo argentino y la inconveniencia de realizar una reforma agraria; la posibilidad de recurrir al auxilio de las potencias occidentales para promover el desarrollo de nuestro país, tema que Frigerio reiterará durante la gestión de gobierno 1958-1962.

Estos aportes, como hemos expuesto, son resignificados por el "Grupo Frigerio" de la década de 1940 y se encuentran maduros para el momento de la llegada de los desarrollistas al poder en la década siguiente.

\section{Conclusiones}

En las páginas precedentes hemos investigado los orígenes de la ideología desarrollista en nuestro país. A través de la indagación hemos mostrado las debilidades de las interpretaciones que atribuyen a Arturo Frondizi alguna participación significativa en su gestación, subsumen al desarrollismo argentino a las ideas de la CEPAL o consideran que su ideario es el resultado de la influencia de la corriente integrada por los teóricos del desarrollo.

Agotadas esas vías explicativas proponemos dos fuentes simultáneas -no serían las únicas, pero sí las principales- para la génesis de la ideología desarrollista: por un lado, los escritos de Alejandro Bunge, citado explícitamente por Frigerio y proveedor de una serie de elementos que lo marcarán: necesidad del proteccionismo para favorecer el crecimiento industrial, utilización de los pioneros 


\section{Revisitando las fuentes ideológicas del desarrollismo: Rogelio Frigerio y el marxismo argentino}

de la economía clásica como marco referencial, rol de las relaciones económicas en la generación de las solidaridades nacionales, participación del capital extranjero, papel orientador del estado sobre la actividad privada. Por otro lado, la vertiente marxista, tal como se expresaba en 1947, introducía al socio político de Frondizi en la necesidad del estudio de leyes económicas necesarias que guían el proceso infra y superestructural, señalaba la presencia de una economía mundial monopólica y del rol modernizador del capital extranjero bajo la regulación estatal. También se presentaba la división del mundo entre potencias industriales y países dependientes en lenguaje leninista y preanunciaba la coexistencia pacífica como circunstancia favorable para pedir el auxilio económico de los Estados Unidos.

Retrocediendo en el tiempo, ubicamos al joven Frigerio en ámbitos cercanos al comunismo argentino desde la década de 1930 para insistir en la posibilidad de esa influencia. Y mencionamos dos ejemplos concretos - los de Ernesto Giudici y Vittorio Codovilla- como fuentes de inspiración probable tanto por la posibilidad de contacto como por la semejanza de las ideas por ellos postuladas. Así, hacia 1940 Giudici se mostraba favorable a la introducción del capital extranjero para modernizar las estructuras económicas del país y -anticipando un leitmotiv frigerista- se oponía a la reforma agraria por considerar que Argentina era una sociedad capitalista y no feudal. Por su parte, Codovilla expresaba la doctrina oficial del PCA llamando al capital extranjero y manteniendo la esperanza de colaboración por parte de las potencias occidentales vencedoras en la conflagración mundial.

Nuestra propuesta es realizar un pequeño homenaje a Guillermo de Ockham y preferir esta explicación sobre los modos de gestación del desarrollismo argentino. Si existen en nuestro país estos antecedentes comprobables y posibles como fuentes ideológicas ¿por qué recurrir a atribuir a un expresidente una influencia imposible de demostrar? ¿por qué insistir en el influjo cepalino, dadas las diferencias esenciales con el frigerismo y la posibilidad de explicar de manera razonable sus coincidencias? ¿por qué entronizar a los teóricos del desarrollo contemporáneos, cuando sus ideas - en la mayoría de los casos- no se corresponden con el desarrollismo y en otros, simplemente no habían sido publicadas al momento de elaboración de la doctrina?

Queda por explicar la evidente "coincidencia desarrollista" en el ámbito latinoamericano y mundial. Con sus diferencias, Helio Jaguaribe en Brasil, Raúl Prebisch en la CEPAL, los planificadores franceses de posguerra, los desarrollistas españoles de la década de 1960, los teóricos del desarrollo citados y el propio Frigerio -entre otros- concuerdan en la necesidad de la industrialización y de romper con el modelo primario exportador como fuente de dependencia.

Una parte de la explicación se contesta con una serie de condiciones estructurales, donde la fase de expansión de las transnacionales estadounidenses y europeas no sería la menos relevante. Sin embargo, cómo hemos expresado, este tipo de interpretaciones resultan insuficientes. En este caso, no explicaría por que las ideologías desarrollistas no acompañaron en todas partes la difusión de las 


\section{Angel Cerra}

multinacionales y tampoco podrían dar cuenta de las importantes diferencias existentes entre ellas

Proponemos más que la transferencia contemporánea de unas a otras, la existencia de un tronco común que informó de un modo directo o indirecto cada una de sus ramas. En esa herencia compartida encontramos la impugnación listiana del librecambio como vía para el progreso de un país; la consagración teórica y práctica del proteccionismo en Estados Unidos y Alemania, la presencia de heréticos periféricos tempranos como Harold Innis en Canadá y Alejandro Bunge en la Argentina, los escritos de Lenin y la experiencia de planificación soviética, la ruptura keynesiana y su crítica a la regulación de las actividades económicas a través de la mano invisible del mercado, entre otros antecedentes.

Las corrientes desarrollistas de los años 50' y 60' tomaron estos precedentes y los combinaron de manera distinta, de acuerdo a un contexto socio-cultural específico y respondiendo a la creatividad de los distintos ideólogos. Por esta vía explicativa, las ideas devuelven a historia su verdadero carácter, donde se combinan estructuras y contingencias de manera indeterminada.

\section{Bibliografía}

Academia de Ciencias de la URSS - Instituto de Economía. (1957 -Primera Edición en español 1955-). Manual de Economía Política. México: Grijalbo.

Acha, 0. (2006). La nación futura: Rodolfo Puiggrós en las encrucijadas argentinas del siglo XX. Buenos Aires: Eudeba.

Altamirano, C. (1998). Desarrollo y desarrollistas. Prismas, Revista de Historia Intelectual $N^{\circ} 2,75-94$.

Anónimo. (1983). Rogelio Frigerio. Buenos Aires: 1983.

Babini, N. (2006). Frondizi y la Argentina Moderna. La forja de una ilusión. Buenos Aires: Gedisa.

Cerra, A. (2002). La formación del pensamiento desarrollista desde la perspectiva de la Historia de las Ideas. Actas IX Encuentro de Cátedras de Ciencias Sociales y Humanísticas para las Ciencias Economicas (págs. 76-84). Mar del Plata: Ediciones Suarez.

Cerra, A. (2003). Los muertos que no mataste. Una explicación de la industrialización argentina a partir de la historia de las ideas. En M. C. Lucchini, El enigma argentino.Empresarios e intelectuales a la búsqueda de un proyecto nacional en el siglo XX. (págs. 91-110). Buenos Aires: Proyecto Editorial. 


\section{Revisitando las fuentes ideológicas del desarrollismo: Rogelio Frigerio y el marxismo argentino}

Cerra, A. (2008). La política petrolera desarrollista a través de la Historia de las Ideas. XV Encuentro de Cátedras de Ciencias Sociales y Humanísticas para las Ciencias Económicas (pág. S/N). Río Cuarto: Universidad Nacional de Río Cuarto.

Cerra, A. (2010). Las raíces ideológicas del desarrollismo argentino: la originalidad de Rogelio Frigerio. Ciencia y Técnica Administraativa, 1- 9.

Cerra, A. (2016). Rogelio Frigerio, la invención del desarrollismo argentino. En A. P. Jáuregui, A. Cerra, \& S. Yazbek, Génesis y construcción del desarrollismo argentino (págs. 73-121). Buenos Aires: Biblos.

Cerra, A. (2018). Políticas desarrollistas en España y la Argentina. Una visión comparativa desde la Historia de las Ideas. En B. Figallo, Desarrollismo, franquismo y neohispanidad. Historias conectadas entre España, América Latina y Argentina (págs. 285-312). Buenos Aires: Teseo - IDEHESI-CONICET (Nodo Rosario).

Codovilla, V. (1945a). Batir el naziperonismo para abrir una era de libertad y progreso. Buenos Aires: Anteo.

Codovilla, V. (1945b). En marcha hacia un mundo mejor. Preguntas y respuestas de una entrevista. Buenos Aires: Partido Comunista Argentino.

Constenla, J. (2011). Sábato, el hombre: la biografía definitiva. Buenos Aires: Sudamericana.

Dosse, F. (2006). La Marcha de las Ideas. Historia de los Intelectuales, historia intelectual. Valencia: Publicacionsde la Universitat de Valencia.

Ferreira de Cassone, F. (2005). Índice de Claridad; una contribución bibliográfica. Buenos Aires: Dunken.

Frigerio, R. (Agosto de 1936). Agosti, Perfil de la Nueva Generación. Claridad(304), $\mathrm{S} / \mathrm{N}$.

Frigerio, R. (Mayo de 1937). Una nueva jornada de afirmación democrática. Claridad(313), S/N.

Frigerio, R. (abril de 1938). Owen, precursor. Claridad(324), S/N.

Frigerio, R. (1959a). El desarrollo argentino y la comunidad americana. Buenos Aires: Ediciones Gure.

Frigerio, R. (1959b). Las condiciones de la victoria - Manual de política argentina. Buenos Aires: Sociedad Editora Argentina.

Frigerio, R. (1979). Síntesis de la Historia Crítica de la Economía Argentina (desde la conquista hasta nuestros días). Buenos Aires: Hachette. 


\section{Angel Cerra}

Gilbert, I. (2009). La Fede. Alistándose para la revolución. La Federación Juvenil Comunista 1921-2005. Buenos Aires: Sudamericana.

Giudici, E. (1940). Imperialismo inglés y liberación nacional-La Argentina y la guerra. Buenos Aires: Editorial Problemas.

Haya de la Torre, R. (23 de Agosto de 1931). Programa Mínimo del Partido Aprista Peruano. Recuperado el 5 de Mayo de 2018, de Marxists.org: https://www.marxists.org/espanol/haya/1930s/1931agosto.htm

Hojvat, C. (1947). Geografía Económico Social Argentina ¿Somos una nación? Buenos Aires: El Ateneo.

Jáuregui, A. P. (2016). Juan José Real, un comunista en la corte del Rey Arturo. En A. C. Aníbal Pablo Jáuregui, Génesis y construcción del desarrollismo argentino (págs. 127-148). Buenos Aires: Biblos.

Jauretche, A. (1984). Barajar y dar de nuevo. Buenos Aires: Los Nacionales Editores.

Keynes, J. M. (1998 -Primera Edición en inglés 1936-). La Teoría General del Empleo, el Interés y el Dinero. Madrid: Editorial Aosta.

Konstantinov, F. (1956). El materialismo histórico. México: Grijalbo.

Longoni, R. (2006). Los jóvenes desarrollistas. Todo es Historia, 6-22.

Love, J. (1996). Las fuentes del estructuralismo latinoamericano. Desarrollo Económico $N^{\circ} 141,391-402$.

Lucchini, C., \& Cerra, A. (2011). Tradiciones heréticas: el nacionalismo económico en Canadá y el industrialismo listiano en la Argentina. Canadiana, 10, 179-198.

Lucchini, C., Blanco, T., \& Cerra, A. (Diciembre de 2000). El pensamiento industrialista argentino en el período de entreguerras: la influencia de List en Bunge. (E. d. Aviv, Ed.) Estudios Interdisciplinarios de América Latina y el Caribe, 11(2), 151170.

Marx, K. (22 de julio de 1853). Futuros resultados de la dominación británica en la India. Recuperado el abril de 2018, de Marxists.org: https://www.marxists.org/espanol/m-e/1850s/1853-india.htm

Morando, M. (2013). Frigerio, el ideólogo de Frondizi. Buenos Aires: A-Z Editores.

Nisbet, R. (1977 -Primera Edición en Inglés 1966-). La formación del pensamiento sociológico. Buenos Aires: Amorrortu.

Ortiz, S. (1962). El Libro Rojo de Rogelio Frigerio. Montevideo: Verax. 


\section{Revisitando las fuentes ideológicas del desarrollismo: Rogelio Frigerio y el marxismo argentino}

Puiggrós, R. (1949 -Primera Edición 1940-). De la colonia a la revolución. Buenos Aires: Partenón.

Real, J. J. (1968). Lenin y las concesiones al capital extranjero. Buenos Aires: Editorial Jorge Alvarez.

Rougier, M. (2016). Sociales UBA. Recuperado el agosto de 2018, de Sociales UBA: http://www.sociales.uba.ar/wp-content/blogs.dir/219/files/2016/06/08.dossier-ROUGIER.pdf

Rouquié, A. (1986). Poder militar y sociedad política en la Argentina - Tomo II. Buenos Aires: Hyspamérica.

Sartori, G. (1999 -Primera Edición en español 1992-). Elementos de Teoría Política. Madrid: Alianza.

Szuterman, C. (1998). Frondizi, la política del desconcierto. Buenos Aires: Emecé.

Recibido: 04/04/2019

Evaluado:20/05/2019

Versión Final: 10/08/2019 